\title{
Competências transversais dos recém-diplomados do ensino superior no mercado global
}

\author{
Luís Araújo Pereira \\ luisaraujopereira@gmail.com \\ NID_RH - Escola Superior de Estudos Industriais e de Gestão - Instituto Politécnico do Porto \\ Ana Cláudia Rodrigues \\ anarodrigues@eu.ipp.pt \\ NID_RH - Escola Superior de Estudos Industriais e de Gestão - Instituto Politécnico do Porto
}

\begin{abstract}
Resumo
O mercado de trabalho está a mudar rapidamente e de muitas formas, nomeadamente, a revolução das tecnologias de informação e comunicação, a globalização, a flexibilização e as alterações da estrutura do trabalho, que conduzem a uma crescente imprevisibilidade e à necessidade de lidar com este contexto de incerteza. Estas mudanças, inevitavelmente, têm implicações no conjunto de competências necessárias para que os trabalhadores sejam capazes de funcionar adequadamente num mercado global cada vez mais competitivo e em constante mutação. Desta forma, nos dias de hoje, o mercado de trabalho requer mais do que conhecimentos teóricos e técnicos, reclama por um conjunto de competências transversais que servirão de suporte e ligação entre o conhecimento técnico e a prática profissional. É neste cenário que emergem as competências transversais que cada vez mais assumem uma importância maior.

O objetivo deste estudo consiste em identificar as competências transversais requeridas aos recém-diplomados do ensino superior no mercado global. Inicialmente, analisa-se o conceito de competência transversal, apresentando algumas definições e assinalando as suas características comuns, destacando ainda a variedade de designações utilizadas para as nomear. No âmbito do estudo foi realizada revisão da literatura nacional e internacional sobre as competências transversais nos diplomados, quer na perspetiva dos próprios diplomados, quer dos empregadores. Através da análise de conteúdo, foram identificadas as competências transversais mais valorizadas por continente e, a partir da análise das mesmas, definiram-se as competências transversais exigidas no mercado global. Finalmente são discutidas as implicações teóricas e empíricas das conclusões deste trabalho.
\end{abstract}

Palavras chave: Mercado de trabalho; mercado de trabalho global; competências transversais; recém-diplomados

\section{Introdução}

Nas últimas décadas ocorreram grandes transformações económicas, tecnológicas, políticas e sociais, que tiveram impacto direto nas organizações, que num ambiente de constante mudança, incerteza e crescente exigência, procuraram tornar-se mais flexíveis, criativas, inovadoras, no sentido da maximização dos seus resultados e de assegurar o seu posicionamento no mercado. Estas transformações, nomeadamente, a revolução das tecnologias de informação e comunicação (TIC), a globalização, a flexibilização e as alterações da estrutura do trabalho e, o domínio da sociedade do conhecimento, não só desafiaram as organizações a refletir sobre o seu negócio e as competências fundamentais para se manterem competitivas no mercado, mas também obrigaram os trabalhadores a refletir sobre a necessidade de desenvolvimento de competências que se 
revelam essenciais para a sua inserção e manutenção num mercado de trabalho cada vez mais global.

O tempo já não é de multidões de empregados facilmente substituíveis, que realizam tarefas parcelares e repetitivas, de acordo com as solicitações e exigências das hierarquias (Le Boterf, 2005). Atualmente, as empresas valorizam indivíduos capazes de tomar iniciativas e decisões, de cooperar eficazmente em projetos descentralizados e de acrescentar valor, através da inovação e desenvolvimento de novos produtos/serviços: "O profissional deve saber fazer face às eventualidades, aos acontecimentos. Deve poder empreender atividades e não apenas executálas" (Le Boterf, 2005: 11).

Desta forma, hoje em dia, as organizações procuram mais do que a especialização no posto de trabalho, pretendem pessoas que possuam conhecimentos e competências que promovam o sucesso. Qualquer profissional nos dias de hoje, por melhor que seja o seu domínio técnico, irá encontrar dificuldades de se inserir e manter no mercado se não for capaz de desenvolver um conjunto de competências transversais (CT) que servirão de suporte e ligação entre o conhecimento técnico e a prática profissional e o tornem distintivo e competitivo no atual contexto de trabalho.

É neste contexto que as CT assumem protagonismo. Em Portugal, os estudos desenvolvidos sobre a temática das CT têm incidido particularmente na identificação das competências valorizadas por diplomados e empregadores atendendo à realidade nacional (Cabral-Cardoso, Estevão \& Silva, 2006; Silva, 2008; Ventura, 2009; Direito et al., 2012) descurando, de certa forma, o contexto global que atualmente caracteriza o mercado de trabalho onde os recémdiplomados se irão movimentar.

Deste modo, e atendendo a que o conhecimento do perfil de competências é fundamental para: (1) as organizações pois é a base para a gestão dos processos de recursos humanos (recrutamento e seleção, avaliação de desempenho, formação e desenvolvimento, etc.), (2) as instituições do ensino superior na medida em que permitirá adequar a sua oferta formativa, adaptar as metodologias pedagógicas e, desenvolver as competências junto dos seus alunos, (3) os próprios estudantes/diplomados de modo a que possam intencionalmente investirem no seu 
$\overline{\text { desenvolvimento, assume-se como relevante realizar uma investigação sobre as CT requeridas no }}$ mercado de trabalho global aos recém-diplomados do ensino superior.

\section{Enquadramento Teórico}

A importância crescente das CT está relacionada com as especificidades do atual contexto marcado pela instabilidade e imprevisibilidade resultante das mudanças e transformações do mercado de trabalho.

A revolução das tecnologias da informação e comunicação (TIC) é, segundo vários autores (Voogt \& Roblin, 2010; Allen \& Van der Velden, 2012), o principal fator impulsionador das transformações do mercado de trabalho, na medida em que têm profundas implicações na forma como organizações e trabalhadores agem e interagem. É indiscutível o modo como tornaram facilmente acessíveis incomensurável quantidade de recursos, permitiram a oportunidade de colaboração em que a proximidade física não é um pré-requisito, provocaram a alteração de diversos conteúdos funcionais.

A globalização gerou oportunidades e imprevisibilidades. Surgiram novos mercados, mas as organizações e trabalhadores enfrentam agora concorrência direta de organizações e trabalhadores de outros países, e necessitam assim de encontrar novas formas de competir.

O mercado de trabalho não se encontra circunscrito à região ou país de origem do trabalhador, e se a mobilidade geográfica é uma realidade que sempre esteve presente no nosso país, tem-se assistido a uma nova vaga de emigração entre os jovens licenciados. Segundo o Instituto de Emprego e Formação Profissional, o número de licenciados desempregados que anulou a inscrição nos centros de emprego para emigrar subiu 49,5\% entre 2009 e 2011. Para além dos destinos tradicionais como a França, Alemanha, Suíça, Estados Unidos, Canadá destacam-se agora outros países como Angola, Brasil, Moçambique, economias emergentes onde as carências técnicas se fazem sentir e geram oportunidades de emprego.

O surgimento de um mercado global e competitivo obrigou as organizações e os profissionais, a encetarem algumas mudanças. No contexto organizacional, verificam-se tendências como a redução do tamanho/dimensão (downsizing), a alteração da estrutura organizacional (tipo horizontal), novas formas de organização do trabalho (equipas e projetos). Assiste-se, igualmente, à flexibilização da relação contratual que coloca em questão o paradigma do 
"emprego certo" e da "carreira para toda a vida". Assim o percurso profissional deve ser autogerido, num espaço sem fronteiras e perspetivado com base em várias ocupações possíveis, num espectro alargado de organizações (Fugate et. al., 2004).

Adicionalmente, a mudança de uma sociedade industrial para uma sociedade do conhecimento requer aos trabalhadores um elevado grau de flexibilidade e a necessidade de atualização permanente, tem profundas implicações para o tipo de competências necessárias à força de trabalho (Voogt \& Roblin, 2010).

Rey (2002) refere que "as novas formas de trabalho industrial e a necessidade, para muitos, de mudar de profissão várias vezes durante a vida e de se adaptar a situações inesperadas exigem algumas potencialidades, que em muito, ultrapassam as competências adquiridas pelas formações específicas" (p. 60). Os empregadores procuram mais do que apenas o diploma, procuram candidatos que possuam os conhecimentos e competências necessários para a sua organização. Desta forma, é essencial que os diplomados adquiram habilidades que complementem a sua formação base e sejam diferenciadoras no mercado de trabalho, isto é, desenvolvam as suas CT.

A literatura no domínio das CT sustenta que o seu desenvolvimento contribui para o sucesso profissional, na medida em que facultam aos trabalhadores as ferramentas necessárias para fazer face às constantes mudanças do mercado e exigência dos empregadores (Rey, 2002; CabralCardoso, Estevão \& Silva, 2006; Van der Klink, Boon \& Schlusmans 2007; Rocha, Gonçalves \& Vieira, 2012).

As CT podem ser definidas como "capacidades genéricas que permitem aos indivíduos ter sucesso numa ampla variedade de tarefas e ocupações" (Assiter, 1995: 12). Podem ser entendidas, segundo Gibbons-Wood e Lange (2000) como competências transferíveis que suportam o desempenho competente em todos os campos, ou ainda como "competências centrais para o desempenho em todos os setores e a todos os níveis" (Chadha, 2006:19). Moreno (2006) avança um pouco mais e assinala que as CT podem ser concebidas como atitudes, capacidades e habilidades do indivíduo que contribuem para uma atuação eficaz em diferentes situações de trabalho, sendo transferíveis de um contexto para outro ao longo da vida.

Não obstante a coexistência de várias definições de CT há dois elementos comuns: podem ser adquiridas através de uma atividade ou disciplina mas passíveis de serem usadas em domínios 
diferentes (Ceitil, 2007) e podem ser aplicadas numa variedade de contextos e conteúdos (Allen, Ramaekers \& Van der Velden, 2005; Ceitil, 2007).

A revisão da literatura reflete também a existência de inúmeras designações de CT. De facto não há uma designação universalmente aceite, atendendo ao país e até mesmo aos autores em análise a designação usada para se reportarem às CT é bastante diversa (Quadro 1).

Quadro1. Designações de competências transversais usadas internacionalmente

\begin{tabular}{|ll|}
\multicolumn{1}{|c|}{ País } & \multicolumn{1}{c|}{ Designações } \\
\hline Estados Unidos & Basic skills, necessary skills, workplace know-how \\
Canadá & Employability skills, core competencies \\
Reino Unido & Core Skills, Key skills, common skills \\
França & Transferable skills \\
Alemanha & Key qualifications \\
Portugal & Competências transversais, competências genéricas \\
Nova Zelândia & Essential skills, soft skills \\
Austrália & Key competencies, employability skills, generic skills \\
Japão & Work skils; employability skills \\
Malásia & Generic skills, employability skills \\
Singapura & Critical enabling skills \\
China & Employability skills \\
África do Sul & Basic Skills \\
\hline
\end{tabular}

Adaptado: National Centre for Vocational Education Research (2003)

Dos vários estudos produzidos sobre esta temática emergem algumas categorizações das CT, destacamos as categorias definidas pelo projeto Tuning Educacional Structures in Europe (2004) que desenvolveu um quadro de competências de referência para a União Europeia com o objetivo de desenvolver resultados de aprendizagem/competências para os programas de ensino superior. Assim, González \& Wagenaar do projeto TUNING propõem 3 categorias de CT: (1) instrumentais, capacidades cognitivas, metodológicas, tecnológicas e linguísticas; (2) interpessoais, capacidades individuais e competências sociais: interação social e cooperação e (3) sistémicas, capacidades relacionadas com o sistema na sua totalidade: combinação da compreensão, sensibilidade e conhecimento que possibilitam ao individuo perceber como as partes de um todo se relacionam e se agrupam.

\section{Metodologia}

Pelas características do estudo, revisão bibliográfica, a sua operacionalização é de natureza qualitativa. Os dados foram recolhidos através do levantamento de produções científicas, sobre 
IV Conferência Investigação e Intervenção em Recursos Humanos - Os Novos Contextos da Gestão de Recursos Humanos

28 e 29 de janeiro de 2013

as competências transversais dos diplomados do ensino superior, na perspetiva dos próprios diplomados e dos empregadores, produzidas entre os anos de 2000 a 2012. Os estudos foram recolhidos nas bases de dados: Biblioteca do Conhecimento Online (B-on), EBSCO; Scientific Electronic Library Online (Scielo); Google Académico; Repositório Científico de Acesso Aberto de Portugal (RCAAP). A pesquisa bibliográfica foi realizada usando-se como descritores as palavras chave "competências transversais", "competências transversais e diplomados"; "competências transversais e ensino superior"; "generic skills", "generic skills and graduates"; "key competencies", "key competencies and graduates", “employability skills”, "employability skills and graduates"; "workplace competencies", "workplace competencies and graduates"; "competencies and higher education", "graduate competencies".

Num primeiro momento, todos os estudos que apresentavam no título uma das palavras chave foram selecionados para leitura. Todavia, das 34 produções científicas encontradas, nacionais e internacionais, somente 22 cumpriam os critérios de inclusão: data de realização a partir do ano de 2000 e apresentação da metodologia que conduziu à identificação das competências transversais. Sempre que possível foi dada preferência a estudos transnacionais. De salientar que na análise da informação utilizaram-se procedimentos de análise de conteúdo, sendo que as categorias foram estabelecidas a priori: temática, país/continente, instrumentos, amostra e principais resultados. Apresenta-se de seguida uma sinopse dos estudos analisados (Quadro 2).

Quadro 2. Sinopse dos estudos relativos às competências transversais e diplomados do ensino superior

\begin{tabular}{|c|c|c|}
\hline $\begin{array}{c}\text { Autor/Projeto/País } \\
\text { Ano }\end{array}$ & Objetivo estudo/amostra/Instrumento & Competências identificadas \\
\hline $\begin{array}{l}\text { Gonzaléz, J., \& Wagenaar, R. } \\
\text { - Tuning Educational } \\
\text { Structures in Europe } \\
\text { (Europa, 2005) }\end{array}$ & $\begin{array}{l}\text { Estudo realizado através de inquérito por questionário } \\
\text { ( } 30 \text { competências) administrado a académicos, } \\
\text { estudantes e empresários de vários países europeus } \\
\text { ( } 27 \text { países, incluindo Portugal), para se pronunciaram } \\
\text { sobre as competências que esperavam encontrar nos } \\
\text { diplomados. }\end{array}$ & $\begin{array}{l}\text { análise e síntese; capacidade de aprender; } \\
\text { resolução de problemas; capacidade de aplicar o } \\
\text { conhecimento; adaptação a situações novas; } \\
\text { preocupação pela qualidade; capacidade para } \\
\text { trabalhar a informação; capacidade de trabalhar } \\
\text { autonomamente; trabalho em equipa; } \\
\text { organização e planeamento; comunicação oral e } \\
\text { escrita; competências interpessoais. }\end{array}$ \\
\hline $\begin{array}{l}\text { Little, B.; Braun, E. \& Tang, } \\
\text { W. - Competences possessed } \\
\text { and required by European } \\
\text { graduates. REFLEX Report. } \\
\text { (Europa, 2008) }\end{array}$ & $\begin{array}{l}\text { Estudo realizado através de inquérito por questionário } \\
\text { (19 competências) e administrado a diplomados de } \\
11 \text { países (Áustria, República Checa, Finlândia, } \\
\text { França, Alemanha, Itália, Holanda, Noruega, } \\
\text { Espanha, Suíça e Reino Unido) que foram convidados } \\
\text { a indicar as competências exigida no seu atual } \\
\text { trabalho. }\end{array}$ & $\begin{array}{l}\text { usar o tempo de forma eficiente; trabalhar bem } \\
\text { sob pressão; domínio do próprio campo ou } \\
\text { disciplina; trabalhar produtivamente com os } \\
\text { outros; capacidade de rapidamente adquirir novos } \\
\text { conhecimentos; coordenar atividades; } \\
\text { comunicação face aos outros; usar computadores } \\
\text { e internet; capacidade de escrever relatórios, } \\
\text { memorandos ou documentos; capacidade de } \\
\text { avançar com novas ideias e soluções. }\end{array}$ \\
\hline
\end{tabular}

(continua) 


\section{Autor/Projeto/País} Ano

The Gallup Organization Employers' perception of graduate employability (Europa, 2010)

\section{Objetivo estudo/amostra/Instrumento}

Estudo realizado através de inquérito por

Estudo realizado através de inquérito por questionário (11 competências) abrangeu todos os 27 Estados Membros da UE, bem como na Noruega, Islândia, Croácia e Turquia. Foram inquiridas empresas que possuíssem pelo menos 50 trabalhadores, numa variedade de setores empresariais e que haviam recrutado diplomados do ensino superior nos últimos 5 anos e/ou estavam a planear contratar diplomados nos próximos 5 anos

Silva, P. - Competências Aplicado inquérito por questionário (40 Transversais dos Licenciados e sua Integração no Mercado de Trabalho

(Portugal, 2008)

Universidade Católica Portuguesa - Projeto FSBiotech - Future Skills for Biotechnology (Portugal, 2009)

Direito, I., Giovane, A. Pereira, A., \& Duarte, A. Competências transversais nas engenharias: comparação de estudantes do Brasil e Portugal (Portugal e Brasil, 2012) competências) a uma amostra de diplomados da Universidade do Minho, bem como, de representantes de entidades empregadoras de diferentes setores, para determinar, entre outros, quais as CT mais valorizadas quer na perspetiva dos empregadores quer na perspetiva dos próprios diplomados

\section{Estudo procura determinar a importância que os} empregadores atribuem às $\mathrm{CT}$ nos profissionais na área da Biotecnologia. Faz parte de um projeto internacional desenvolvido entre cinco países europeus (Alemanha, Irlanda, Polónia, Portugal e Reino Unido). Os resultados das empresas portuguesas foram obtidos a partir da aplicação de um inquérito por questionário (26 competências)

\section{Os participantes deste estudo foram 104 estudantes} em formação e estudantes recentemente diplomados, de diferentes cursos de engenharia da Universidade Federal de Minas Gerais, Brasil $(n=54)$ e da Universidade de Aveiro, Portugal $(n=50)$. Os estudantes foram instruídos a avaliar o domínio atual das competências e a sua importância para o mercado de trabalho através de um questionário com 29 competências.
NACE - National Association of Colleges and Employers Job Outlook 2012

(EUA, 2012)

Anualmente a NACE inquire os seus membros empregadores sobre os seus planos de contratação e outras questões relacionadas com o emprego, nomeadamente, as competências que procuram nos diplomados no momento da sua contratação, a fim de projetar as tendências do mercado para os recém-formados. Estudo realizado através de inquérito por questionário (19 competências) entre agosto e setembro de 2011, tendo 244 emoresas respondido ao mesmo.

University of Victoria Competency kit - 10 core competencies (used in any workplace) (Canada, 2011)

Beneitone, P., Esquetini, C., González, J., Maletá, M., Siufi,

G. \& Wagenaar, R. - Alfa

Tuning América Latina (América Latina, 2007)
Estudo realizado junto de empregadores do Canada, no qual foi solicitado que identificassem as competências essenciais que os trabalhadores deveriam possuir.

Estudo no qual foram consultados académicos, gaduados, alunos e empregadores de vários países da América Latina (18 países), para se pronunciaram sobre as competências que esperavam encontrar nos diplomados a partir de uma lista de 27 competências previamente validada.

\section{Competências identificadas}

trabalho em equipa; competências específicas do setor de atividade; competências de comunicação; competências de informática; capacidade de adaptação e ação em situações novas; competências de leitura /escrita; competências de análise e de resolução de problemas; competências de planeamento e organização; competências de tomada de decisão.

resolução de problemas;

planeamento/organização; tecnologias de informação e comunicação; motivação; relacionamento interpessoal; disponibilidade para a aprendizagem contínua; adaptação à mudança; auto-confiança.

relacionamento interpessoal ; aprendizagem; trabalho em equipa; melhoria contínua/excelência: comunicação; ética e integridade; pensamento crítico; resiliência e motivação; responsabilidade; pontos pessoais positivos; compromisso e persistência.

\section{Portugal}

Networking; capacidade de resolver conflitos; visão sistêmica; adaptação à mudança; atenção ao detalhe; autonomia; trabalho em equipa; gestão do tempo; comunicação escrita. Brasil

responsabilidade; trabalho em equipa; proatividade e iniciativa; cumprimento de prazos; resolução de problemas; gestão do tempo; saber ouvir; organização de trabalho; tolerância à pressão.

trabalho em equipa; capacidade de comunica verbalmente com pessoas dentro e fora da organização; tomar decisões e resolver problemas; obter e processar informações; planear, organizar e priorizar o trabalho; analisar dados quantitativos; conhecimento técnico relacionado com o trabalho; proficiência em programas informáticos; capacidade de criar e/ou editar relatórios escritos; capacidade de vender ou influenciar os outros.

gestão pessoal; comunicação; gestão da informação; pesquisa e análise; planeamento e gestão de tarefas; trabalho em equipa; compromisso com a qualidade; comportamento profissional; responsabilidade social; aprendizagem contínua.

capacidade de abstração, análise e síntese; capacidade de aplicar os conhecimentos na prática; conhecimentos sobre a área de estudo e a profissão; capacidade para identificar, delinear e resolver problemas; capacidade de pesquisa; capacidade de aprender e atualizar-se permanentemente; compromisso ético.

(continua) 


\section{Autor/Projeto/País} Ano

Singh, G., \& Singh, S. -

Malaysian graduates' employability skills

(Malásia, 2008)

Held by Employers of Chinese

Graduates' Employability

Skills

(China)

2010

Matsumoto, Shinsaku, Asai, C.,

Tajima, H., \& Kinoshita, T. -

Employability checklist

(Japão, 2001)

(Jара̃o, 2001)

\section{Singapore}

Workforce Development

Agency - Singapore

Employability Skills System

(ESS)

(Singapura, 2004)

Education and Manpower

Bureau - Employers'

Satisfaction

with First Degree Graduates

Performance

(Hong Kong, 2000)

Rainsbury, E., Hodges, D.

Burchell, N., \& Lay, M. -

Ranking workplace

competencies: student and

graduate perceptions.

(Nova Zelândia, 2002)

Hodges, D. \& Burchell, N. -

Business Graduate

Competencies: Employers'

Views on Importance and

Performance

(Nova Zelândia, 2003)

DEEWR - Australia's

Department of Education,

Employment and Workplace

Relations - Employability

Skills Framework

(Austrália, 2011)

\section{Griesel, H. \& Parker, B. -}

Graduate Attributes -

A baseline study on South

African graduates from the

perspective of employers.

(África do Sul, 2009)

\section{Objetivo estudo/amostra/Instrumento}

Estudo realizado com recém-licenciados e respetivos empregadores de organizações de todo o Vale Klang, aos quais foi aplicado questionário (11

competências), onde era pedido que identificassem a importância que atribuíam às competências. Participaram 211 empregadores e 257 diplomados.

Estudo realizado no terceiro trimestre de 2009, com o objetivo de identificar as competências de empregabilidade necessárias no mercado de trabalho. Os dados foram obtidos através da aplicação de inquérito por questionário (14 competências) a recém-licenciados e respetivos empregadores (424) em organizações na China.

Estudo realizado com empregadores de organizações japonesas, aos quais foi aplicado questionário, onde entre outros fatores, era pedido que identificassem a importância que atribuíam às competências. Das 10000 empresas contactadas, responderam 2176.

Estudo realizado com o objetivo de desenvolver um referencial de competências, tendo como base a realização de inquérito por questionário às organizações a nível nacional, as quais foram consultadas para identificar as competências de empregabilidade que mais valorizavam.

Inquérito realizado junto de empregadores, a da região de Hong Kong, onde era solicitado que avaliassem os recém licenciados que tinham ingressado na sua força de trabalho e identificassem as competências transversais que consideravam mais importantes.

Estudo com estudantes e diplomados da área de negócios, aos quais através de questionário pediram que assinalassem o grau de importância que atribuiam a cada uma das competências presentes numa listagem de 24 competências identificadas a partir da literatura.

Estudo realizado junto de empregadores em Auckland, Nova Zelândia, através de inquérito por questionário onde foi solicitado que classificassem o nível de importância que atribuíam a 25 competências para diplomados a exercer atividade no seu primeiro ano de trabalho.

O projeto visou identificar as competências desejadas pelas empresas. Analisou estudos sobre CT,

realizados na Austrália e internacionalmente. Incluiu também extensiva consulta a um amplo leque de organizações e setores de atividade, tendo cerca de 700 pessoas participado através de entrevistas individuais, focus groups, consultas públicas ou de prestação de feedback escrito.

Estudo realizado pelo Higher Education South Africa através da aplicação de questionário (33 competências) a uma amostra de empregadores SulAfricanos (equilíbrio proporcional entre pequenas, médias e grandes empresas), responderam 99 . Visava fazer balanço das expectativas dos empregadores e a sua avaliação da qualidade dos diplomados.

\section{Competências identificadas}

competências de tecnologia, informação e comunicação; trabalho em equipa; relacionamento interpessoal; proficiência em inglês; comunicação; organização pessoal e gestão de tempo; adaptabilidade; competências de tomada de risco; criatividade.

comunicação;competência de aprendizagem; relacionamento interpessoal; trabalho em equipa; integridade; atitude positiva; resolução de problemas e tomada de decisão; gestão de pessoal; gestão do tempo; organização e planeamento; inovação.

\section{comunicação; competências interpessoais;} organização e funcionamento de uma organização;competência cognitiva/capacidade concetual; auto-aprendizagem; força mental; resposta a mudanças; auto-suficiência e auto valorização.

literacia e numeracia profissional; competências de tecnologias de informação e comunicação; resolução de problemas e tomada de decisão; iniciativa e empreendedorismo; comunicação e gestão das relações; aprendizagem ao longo da vida; mentalidade global; auto-gestão.

atitude no trabalho; competências interpessoais; análise e resolução de problemas; proficiência em inglês; competência numérica; literacia em tecnologias da informação; competências de gestão; proficiência na língua chinesa.

literacia tecnológica; orientação para o cliente; trabalho em equipa e cooperação; auto-confiança; iniciativa; vontade para aprender; flexibilidade; relacionamento interpessoal.

capacidade e vontade de aprender; energia e paixão; trabalho em equipa e cooperação; comunicação interpessoal; orientação para o serviço ao cliente; ordem, qualidade e precisão; flexibilidade; resolução de problemas; orientação para os resultados; iniciativa.

competências de comunicação; trabalho em equipa; resolução de problemas; iniciativa e competências de empreendimento; planeamento e organização;competências de auto-gestão; competências de aprendizagem; competências tecnológicas.

abertura e flexibilidade; capacidade de pesquisar e aceder a informação; vontade de aprender; auto-motivação e iniciativa; competências de informática; capacidade de usar a informação; capacidade de aplicar o conhecimento a situações novas; resolução de problemas.

(continua) 


\begin{tabular}{|c|c|c|}
\hline $\begin{array}{c}\text { Autor/Projeto/País } \\
\text { Ano }\end{array}$ & Objetivo estudo/amostra/Instrumento & Competências identificadas \\
\hline $\begin{array}{l}\text { Wim Kouwenhoven - } \\
\text { Designing for competence in } \\
\text { Mozambique: towards a } \\
\text { competence-based } \\
\text { curriculum for the Faculty of } \\
\text { Education of the Eduardo } \\
\text { Mondlane University } \\
\text { (Moçambique, 2003) }\end{array}$ & $\begin{array}{l}\text { Estudo realizado por questionário ( } 25 \text { competências) } \\
\text { aplicado a } 61 \text { informantes-chave do setor público, } \\
\text { privado e ensino superior moçambicano para } \\
\text { assinalarem aquelas que consideravam mais } \\
\text { importantes. Participantes que poderiam dar mais } \\
\text { informação atendendo a critérios como o cargo que } \\
\text { ocupavam, a experiência profissional, foram } \\
\text { entrevistados. }\end{array}$ & $\begin{array}{l}\text { comunicação; resolução de problemas; } \\
\text { aprendizagem contínua; tecnologias de } \\
\text { informação e comunicação; competências } \\
\text { interpessoais; gestão da informação; planeamento } \\
\text { e organização de atividades; liderança. }\end{array}$ \\
\hline $\begin{array}{l}\text { Raimo Ndapewa Naanda - The } \\
\text { integration of identified } \\
\text { employability skills into the } \\
\text { namibian vocational education } \\
\text { and training curriculum } \\
\text { (Namibia, 2010) }\end{array}$ & $\begin{array}{l}\text { Estudo realizado através de um inquérito por } \\
\text { questionário ( } 39 \text { competências), enviado a } 493 \\
\text { empregadores dos quais } 244 \text { responderam, } \\
\text { assinalando as as competências de empregabilidade } \\
\text { que mais valorizam nos diplomados quando entram } \\
\text { no mercado de trabalho. Adicionalmente foram } \\
\text { realizadas entrevistas a alguns dos empregadores. }\end{array}$ & $\begin{array}{l}\text { trabalho em equipa; gestão do tempo; atitude } \\
\text { positiva; resolução de problemas; } \\
\text { lidar com várias tarefas; planeamento; } \\
\text { pensamento crítico; aprendizagem contínua. }\end{array}$ \\
\hline $\begin{array}{l}\text { Alao, A.A, Pilane C.D, } \\
\text { Mabote M.M, Setlhare K, } \\
\text { Mophuting K, } \\
\text { Semphadile K.M, Odirile L.W, } \\
\text { Kgathi P.L.; Mmapatsi, S. - } \\
\text { Employer Satisfaction Survey } \\
\text { of The University of Botswana } \\
\text { Graduates } \\
\text { (Botswana, 2009) }\end{array}$ & $\begin{array}{l}\text { Estudo realizado a partir de dois questionários, um } \\
\text { primeiro dirigido aos gestores de recursos humanos } \\
\text { para identificar se a empresa empregava diplomados e } \\
\text { um segundo dirigido aos supervisores dos diplomados } \\
\text { no qual era solicitado que assinalassem a importância } \\
\text { das competências dos diplomados para a organização. } \\
\text { Os dados resultaram das respostas de } 61 \text { supervisores } \\
\text { de } 32 \text { organizações que empregavam } 622 \text { diplomados. }\end{array}$ & $\begin{array}{l}\text { competências de comunicação; competências de } \\
\text { informática; competências interpessoais; } \\
\text { pensamento critico e resolução de problemas; } \\
\text { flexibilidade e adaptabilidade; planeamento e } \\
\text { organização; liderança/gestão; gestão do tempo; } \\
\text { análise e pesquisa. }\end{array}$ \\
\hline
\end{tabular}

\section{Análise e Discussão dos dados}

Como se pode constatar no Quadro 2, o instrumento de investigação utilizado na generalidade dos estudos foi o questionário, porém o número de CT apresentadas aos inquiridos é bastante variável, por um lado encontramos estudos com 40 competências (Silva, 2008) e 39 competências (Naanda, 2010), por outro lado encontramos estudos com 11 competências (The Gallup Organization, 2010; Singh \& Singh,2008). Os resultados apresentados, isto é as competências identificadas para cada estudo, reportam-se àquelas que reuniram maior consenso e às quais foi atribuído um maior nível de importância por parte dos inquiridos.

As amostras dos estudos reportaram-se aos diplomados e empregadores, sendo que a maioria dos estudos $(59,1 \%)$ inquiriram empregadores, seguindo-se aqueles que inquiriram empregadores e diplomados $(22,7 \%)$ e finalmente aqueles que inquiriram apenas diplomados (18,2\%). De destacar que nos estudos que indagaram diplomados e empregadores os resultados encontrados evidenciaram parecer haver consenso entre diplomados e empregadores relativamente ao que consideraram ser as competências transversais mais importantes.

No que concerne ao perfil de CT identificado, foram realizadas duas análises, uma primeira que visou a identificação das CT mais valorizadas por continente e posteriormente a análise das competências em termos globais. Para a primeira análise, os 22 estudos encontrados foram divididos pelos respetivos continentes, ficando assim distribuídos: 6 estudos europeus, 4 estudos 
americanos, 5 estudos asiáticos, 4 estudos africanos e 3 estudos da Oceania. Os resultados obtidos encontram-se no Quadro 3 que de seguida se apresenta.

Quadro 3. Perfil de competências transversais por continente

\begin{tabular}{|c|c|c|c|c|c|c|c|c|c|}
\hline Europa & $\mathbf{n}=$ & América & $\mathbf{n}=$ & Ásia & $\mathbf{n}=$ & África & $\mathbf{n}=$ & Oceania & $\mathbf{n}=$ \\
\hline $\begin{array}{l}\text { - trabalho em } \\
\text { equipa } \\
\text { - adaptação à } \\
\text { mudança } \\
\text { - planeamento e } \\
\text { organização } \\
\text { - aprendizagem } \\
\text { contínua } \\
\text { - comunicação } \\
\text { - tecnologia de } \\
\text { informação e } \\
\text { comunicação } \\
\text { - resolução de } \\
\text { problemas } \\
\text { - relacionamento } \\
\text { interpessoal }\end{array}$ & 4 & $\begin{array}{l}\text { - } \text { trabalho em } \\
\text { equipa } \\
\text { - resolução de } \\
\text { problemas } \\
\text { - pesquisa e } \\
\text { análise } \\
\text { - organização e } \\
\text { planeamento } \\
\text { - comunicação } \\
\text { - conhecimento } \\
\text { técnico } \\
\text { - aprendizagem } \\
\text { contínua } \\
\text { - compromisso } \\
\text { ético }\end{array}$ & $\begin{array}{l}2 \\
2 \\
2 \\
2\end{array}$ & $\begin{array}{l}\text { - relacionamento } \\
\text { interpessoal } \\
\text { - organização e } \\
\text { planeamento } \\
\text { - comunicação } \\
\text { - tecnologia de } \\
\text { informação e } \\
\text { comunicação } \\
\text { - resolução de } \\
\text { problemas e } \\
\text { tomada de } \\
\text { decisão } \\
\text { - aprendizagem } \\
\text { - trabalho em } \\
\text { equipa }\end{array}$ & $\begin{array}{l}3 \\
3\end{array}$ & $\begin{array}{l}\text { - } \text { resolução de problemas } \\
\text { - planeamento e } \\
\text { organização } \\
\text { - tecnologia de informação } \\
\text { e comunicação } \\
\text { - aprendizagem contínua } \\
\text { - comunicação } \\
\text { - competências } \\
\text { - } \text { interpessoais } \\
\text { - glexibilidade } \\
\text { - análise e pesquisa } \\
\text { - liderança }\end{array}$ & $\begin{array}{l}4 \\
3 \\
3 \\
3 \\
2 \\
2 \\
2 \\
2 \\
2 \\
2 \\
2\end{array}$ & $\begin{array}{l}\text { - trabalho em } \\
\text { equipa } \\
\text { - aprendizagem } \\
\text { - iniciativa } \\
\text { - relacionament } \\
\text { o interpessoal } \\
\text { - orientação } \\
\text { para o cliente } \\
\text { - resolução de } \\
\text { problemas } \\
\text { - competências } \\
\text { tecnológicas } \\
\text { - flexibilidade }\end{array}$ & $\begin{array}{l}2 \\
2 \\
2 \\
2\end{array}$ \\
\hline
\end{tabular}

As CT que representam cada continente respeitam o critério de estarem presentes em pelo menos metade dos estudos em análise: Europa (8 competências); América (7); Ásia (7); África (10); e Oceania (8). Estas diferenças indiciam que os estudos efetuados no continente africano identificaram um perfil de CT relativamente semelhante entre si, pelo contrário no continente americano e asiático verificou-se uma maior diversidade das competências dos perfis identificados em cada um dos estudos. De salientar, no entanto, que a mesma competência surge por vezes com denominação distinta em diferentes estudos, o que obrigou a uma apreciação das suas definições para verificar a sua correspondência.

De um modo geral verificou-se que o perfil de CT que representa cada continente apresenta competências nas 3 categorias definidas pelo projeto Tuning (instrumentais, interpessoais e sistémicas). $\mathrm{Na}$ generalidade dos continentes, observa-se uma maior prevalência das competências instrumentais, sendo que esta tendência apenas não se verifica na Oceania onde as competências sistémicas se encontram em maior número.

$\mathrm{Na}$ análise das competências mais valorizadas em temos globais, realizaram-se dois procedimentos de análise: (1) observação dos resultados por continente para apurar as CT que surgiam com mais frequência; (2) investigação da presença das CT nos 22 estudos em análise. Os resultados dos dois procedimentos encontram-se no Quadro 4 que de seguida se apresenta. 
Quadro 4. Perfil de competências transversais global

\begin{tabular}{|lcc|}
\multicolumn{1}{|c}{ Procedimento 1 } & Procedimento 2 \\
\hline resolução de problemas $(\mathrm{n}=5)$ & Frequência & \% \\
aprendizagem contínua $(\mathrm{n}=5)$ & 15 & 68,2 \\
trabalho em equipa $(\mathrm{n}=4)$ & 15 & 68,2 \\
planeamento e organização $(\mathrm{n}=4)$ & 15 & 68,2 \\
comunicação (n=4) & 12 & 68,2 \\
tecnologia de informação e comunicação $(\mathrm{n}=4)$ & 12 & 54,5 \\
relacionamento interpessoal $(\mathrm{n}=4)$ & 11 & 54,5 \\
flexibilidade e adaptação $(\mathrm{n}=3)$ & 10 & 50 \\
\hline
\end{tabular}

Como se pode apurar no Quadro 4, os resultados encontrados nos dois procedimentos são semelhantes. Na análise dos resultados por continente evidenciaram-se $8 \mathrm{CT}$, adotando o critério de estarem presentes em pelo menos metade dos clusters por continente, tendo-se posteriormente verificado que essas mesmas 8 competências sobressaíram igualmente na análise geral dos 22 estudos. Constatou-se que a quase totalidade das CT (7) identificadas na análise dos resultados por continente se encontravam presentes em pelo menos $50 \%$ dos estudos, apenas a CT flexibilidade e adaptação, presente em 10 dos estudos, não cumpre essa condição. Subjacente a esta situação, encontra-se o facto de aquela competência não surgir em nenhum estudo do continente americano onde o enfoque dos empregadores e diplomados foi sobretudo nas competências instrumentais.

Depreende-se do atrás exposto, que não obstante as especificidades de cada continente, as competências assinaladas e valorizadas por empregadores e diplomados foram bastante aproximadas. Observa-se, inclusivamente que as $8 \mathrm{CT}$ globais correspondem na íntegra às competências identificadas para a Europa, incluem todas as competências da América e Ásia e englobam a quase totalidade das competências da África e Oceania.

Verificou-se, igualmente, que o perfil de CT global engloba competências nas 3 categorias do Projeto Tuning, instrumentais (resolução de problemas, planeamento e organização, comunicação, tecnologia de informação e comunicação), interpessoais (trabalho em equipa, relacionamento interpessoal) e sistémicas (aprendizagem contínua, flexibilidade e adaptação).

\section{Conclusão}

Um fator que emerge dos resultados dos estudos em análise é que os diplomados reconhecem a importância das CT para a sua inserção no mercado de trabalho e progresso profissional e os 
empregadores valorizam as CT dos seus colaboradores e procuram essas mesmas competências no momento de os recrutar. Assim, a identificação do perfil de CT global, surge como um referencial para organizações, instituições do ensino superior, estudantes e diplomados, face ao qual poderão, avaliar o seu domínio, tomar decisões, definir ações para o seu desenvolvimento.

Ao contrário das competências técnicas que estão associadas a desempenhos específicos de cada atividade/profissão, as CT revelaram-se efetivamente transversais. Não obstante as diferenças existentes entre os vários continentes, quando se analisam as competências mais valorizadas em cada um, no séc. XXI, observa-se que o perfil de competências é bastante semelhante, o que indicia e reforça a sua transversalidade. Isto é, são comuns a vários contextos, e por isso isentas de especificidades profissionais e situacionais. A literatura sobre o conceito das CT é assim reforçada pelos estudos empíricos.

Salienta-se, porém, que a não existência de uma designação universalmente aceite, antes pelo contrário cada país e até mesmo diferentes autores utilizam distintas e variadas designações para se reportarem às CT revela-se um obstáculo na pesquisa e na identificação da temática. Acresce ainda que uma mesma competência pode assumir diferentes denominações, o que mais uma vez poderá ser uma dificuldade para a comparabilidade e análise de resultados.

Uma das principais limitações deste estudo reside na sua amostra, 22 estudos. Pensamos que poderia ser interessante desenvolver uma investigação mais abrangente. Adicionalmente, o carácter exploratório do estudo limitou a comparação de resultados com outros estudos realizados, pois não encontrámos nenhum outro estudo que procurasse identificar as competências no mercado global.

\section{Bibliografia}

Alao , A.A, Pilane C.D, Mabote M.M, Setlhare K, Mophuting K, Semphadile K.M, Odirile L.W, Kgathi P.L.; Mmapatsi, S. (2009). Employer Satisfaction Survey of The University of Botswana Graduates. International Journal of Contemporary Issues in Education and Psychology, 1 (3), 17-34.

Allen, J. \& Van der Velden, R. (2012). Skills for the 21st Century: Implications for Education. Maastricht: Researchcentrum voor Onderwijs en Arbeidsmarkt,

Allen, J., Ramaekers, G., \& Van der Velden, R. (2005). Measuring competencies of higher education graduates. New Directions for Institutional Research, 126, pp. 49-59.

Assiter, A. (1995). Transferable Skills in Higher Education. London: Kogan

Australia's Department of Education, Employment and Workplace Relations - DEEWR (2011). Employability Skills Framework. Austrália: Canberra.

Beneitone, P., Esquetini, C., González, J., Maletá, M., Siufi, G. \& Wagenaar, R. (2007). Reflexões e perspectivas do Ensino Superior na América Latina: relatório final Projeto Tuning América Latina 2004-2007. Bilbao: Universidad de Deusto. 
Cardoso, C., Estêvão, C., \& Silva, P. (2006). Competências Transversais dos Diplomados do Ensino Superior, Perspetiva dos Empregadores e Diplomados. Guimarães: TecMinho.

Ceitil, M. (2007). Gestão e Desenvolvimento de Competências. Lisboa: Sílabo.

Chadha, D. (2006). A curriculum model for transferable skills development. Engineering Education, 1(1), pp.19-24.

Direito, I., Giovane, A., Pereira, A., \& Duarte, A. (2012). Competências transversais nas engenharias: comparação de estudantes do Brasil e Portugal. Disponível em http://www.abenge.org.br/CobengeAnteriores/2012/artigos/103636.pdf (consultado em 13 de dezembro de 2012)

Education and Manpower Bureau (2000). Employers' Satisfaction with First Degree Graduates Performance. China: Hong Kong.

European Commision (2010). Employers' perception of graduate employability: analytical report. Eurobarometer - Flash Eurobarometer, 304 - The Gallup Organization, Hungary.

Fugate, M., Kinicki, A.J., \& Ashforth, B.E. (2004). Employability: A psycho-social construct, its dimensions, and applications. Journal of Vocational Behavior, 65, pp. 14-38.

Gibbons-Wood, D. and Lange, T., 2000. Developing Core Skills: Lessons from Germany and Sweden. Education and Training, 42, pp. 24-32.

Gonzaléz, J., Wagenaar, R. (2005). Tuning Educational Structures in Europe II. Universities' contribution to the Bologna Process. Bilbao: Universidade de Deusto.

Griesel, H. \& Parker, B. (2009). Graduate Attributes - A baseline study on South African graduates from the perspective of employers. Higher Education South Africa \& the South African Qualifications Authority.

Hodges, D. \& Burchell, N. (2003). Business Graduate Competencies: Employers' Views on Importance and Performance. AsiaPacific Journal of Cooperative Education, 4(2), pp. 16-22.

Koc, E., \& Koncz, A. (2012). Job Outlook 2012. Bethlehem: National Association of Colleges and Employers.

Le Boterf, G. (2005). Construir as competências individuais e colectivas. Porto: Edições ASA.

Liling, L. (2010). The Perceptions Held by Employers of Chinese Graduates’ Employability Skills. M\&D Forum, pp.473-479.

Little, B., Braun, E. \& Tang, W. (2008). Competences possessed and required by European graduates. REFLEX Report to HEFCE, 4. Higher Education Funding Council for England, Bristol, UK.

Matsumoto, Shinsaku, Chiaki Asai, Hiromi Tajima \& Toshi Kinoshita (2001). Experimental Research into the Degree of Attractiveness of Multidimensional Companies and Employability Checklists. Kenkyu Kiyo (Japan Institute of Labour), 21, pp. $1-41$.

Moreno, M. L. R. (2006). Evaluación, balance y formación de competencias laborales transversales: propuestas para mejorar la calidad en la formación profesional y en el mundo del trabajo. Laertes Educación: Barcelona.

Naanda, Raimo N. (2010). The integration of identified employability skills into the namibian vocational education and training curriculum. Tese de Doutoramento em Filosofia da Educação. Stellenbosch University - Faculty of Education. 259 pp.

National Centre for Vocational Education Research (2003). Defining generic skills: At a glance. Adelaide: NCVER.

Rainsbury, E., Hodges, D., Burchell, N., \& Lay, M. (2002). Ranking workplace competencies: student and graduate perceptions. Asia-Pacific Journal of Cooperative Education, 3(2), pp. 8-18.

Rey, B. (2002). As competências transversais em questão. São Paulo: Artmed Editora.

Rocha, J., Gonçalves, C., \& Vieira, D. (2012). Competências transversais: perceção de estudantes do $1^{\circ}$ ano do ensino superior. Apoio psicológico no ensino superior: um olhar sobre o futuro: actas do II congresso RESAPES-AP, pp. 196-206.

Silva, P. (2008). Competências Transversais dos Licenciados e sua Integração no Mercado de Trabalho. Tese de Mestrado em Gestão de Recursos Humanos. Universidade do Minho - Escola de Economia e Gestão. 145 pp.

Singapore Workforce Development Agency (2004). The Singapore Employability Skills System (ESS). Singapura: Singapura.

Singh, G., \& Singh, S. (2008). Malaysian graduates' employability skills. Unitar E-Journal, 4 (1), pp. 15-45.

University of Victoria (2011). Competency kit - 10 core competencies (used in any workplace). Canada: Victoria.

Van der Klink, M., Boon, J., \& Schlusmans, K. (2007). Competências e ensino superior profissional: presente e futuro. Revista Europeia de Formação Profissional, 40, pp. 72-89.

Ventura, M. (2009). Projeto FS-Biotech - Future Skills for Biotechnology: Biotechnology Skills Profile Report. Porto: Universidade Católica.

Voogt J. \& Roblin, N. (2010). 21 st Century Skills: Discussion Paper. Enschede: Universiteit Twente.

Wim Kouwenhoven (2003). Designing for competence in Mozambique: towards a competence-based curriculum for the Faculty of Education of the Eduardo Mondlane University. Tese. University of Twente, Enschede. 450 pp. 